\title{
Influence of Reaction Temperature on the Controlled Growth of Mg-Al LDH Film
}

\author{
Liang Wu ${ }^{*}$, Zhicheng Zheng, Fusheng Pan ${ }^{* *}$, Aitao Tang, Gen Zhang, Lei Liu
}

School of Materials Science and Engineering, Chongqing University, Chongqing 400044, China. *E-mail address: wuliang@ cqu.edu.cn.

***mail address: fspan@cqu.edu.cn.

doi: $10.20964 / 2017.07 .74$

Received: 23 February 2017 / Accepted: 24 April 2017 / Published: 12 June 2017

The Mg-Al layered double hydroxides (Mg-Al LDH) film was fabricated on anodized magnesium alloy AZ31 at different reaction temperature by in-situ hydrothermal treatment method. The reaction solution contained only one kind of trivalent cation $\mathrm{Al}^{3+}$, and the divalent cation $\mathrm{Mg}^{2+}$ is provided by the anodic oxide films. The structure, composition and morphology of the Mg-Al LDH films were investigated via XRD, FI-IR and SEM, respectively. The corrosion resistance of films was studied using potentiodynamic polarization and electrochemical impedance spectroscopy. The SEM images show that the compactness of LDHs increases with the increase of the reaction temperature. The results of XRD and FT-IR indicate that the crystallinity of films was improved with the increase of reaction temperature. The results of potentiodynamic polarization and electrochemical impedance spectrum show that the corrosion resistance was improved with the increase of reaction temperature. The influence mechanism of reaction temperature on the controlled growth of $\mathrm{Mg}-\mathrm{Al} \mathrm{LDH}$ films was investigated subsequently.

Keywords: magnesium alloy; reaction temperature; layered double hydroxides; corrosion resistance; anodic oxide film

\section{$\underline{\text { FULL TEXT }}$}

(C) 2017 The Authors. Published by ESG (www.electrochemsci.org). This article is an open access article distributed under the terms and conditions of the Creative Commons Attribution license (http://creativecommons.org/licenses/by/4.0/). 